in the biosynthesis of a protein molecule. In the living cell, three different forms of ribonucleic acid (RNA) take their parts in this synthesis; one is the 'messenger' carrying instructions for the amino-acid sequence from the deoxyribonucleic acid (DNA) of the nucleus to the site of protein synthesis. The DNA carries the hereditary information of the cell and is copied at every cell reproduction. Our understanding of these processes is being built up from very diverse experimental studies. X-ray studies of DNA fibres have shown the helical structure of the molecules with paired purine and pyrimidine bases, and allowed Watson \& Crick to suggest the mechanism of replication - so that the information contained in the sequence of bases may be passed on from parent to daughter cell. Suitably crystalline RNA fibres have more recently been obtained and have shown these molecules to be largely helical too. Isotopic tracer experiments have been used to follow the fate of different components of the protein and nucleic acid synthesising systems both in vivo and in vitro. Genetic studies on bacteria, with chemically induced mutations, have shown that the code word for one amino acid consists of three bases in the DNA chain; biochemical experiments are beginning to show which three bases constitute each code word.

Dr Perutz, in his second and third lectures, has drawn together and described in outline many of the key experiments in these different fields, and showed what is proved by each. It is a most useful survey, and fascinat. ing to read; each argument must be closely and carefully followed, and probably much more material has been presented in this short space than the newcomer can hope to appreciate fully in one reading.

The first of the three lectures describes the results of the $\mathrm{X}$-ray analyses of the crystal structures of the protein molecules myoglobin and haemoglobin, the interpretation of the electron-density maps at limited resolution, the detailed architecture of these large and biochemically important molecules, and the dependence of this architecture on their chemical constitution. The methods of the X-ray analysis are not discussed at all; in fact very little indication is given of the years of toil, on the part of Dr Perutz and his colleagues, which preceded these beautiful results, years during which the intermediate results were of interest to crystallographers but had very little significance for biologists. But now there is a wealth of information of great interest to biologist, chemist, and crystallographer, and it is a pleasure to hear (or read) Dr Perutz's account of this.

The book provides, therefore, an exciting introduction to molecular biology (for the beginner who already has some background of chemistry and biology), or, for the reader already familiar with a part of it, a good survey of the wider field and the relation of one development to another. (It is not intended, however, to be an exhaustive review.) There is an appendix outlining a few advances made since the lectures were given, and a useful list of references up to mid 1962.

MarJorie M. Harding
Department of Chemistry
The University of Edinburgh
Edinburgh 9
Scotland

Dana's System of Mineralogy, Vol. III. 7th ed. By C. Fronder. Pp. 334, with 114 figs. and 50 tables. New York, London: Wiley 1962. Price \$7.95.

Volume III of Dana's System of Mineralogy contains a dotailod description of the silica minerals, especially of quartz, which occupies about three-quarters of the contents. The rest of this volume is devoted to the remaining polymorphs, including the new synthetic high-pressure modifications, some of which have subsequently been discovered as natural minerals. The main concern of this handbook is the detailed description of the morphological, physical and chemical properties of the minerals in question. The crystal forms observed are broadly discussed. There is no doubt that this collection of data on a single chemical compound is most valuable for all scientific research on this subject. On the other hand the reviewer feels that the structural data are not treated quite in accordance with their general importance for all properties here discussed. The description of the structures and the mutual relations of the polymorphs is discussed in a formal manner only, e.g. the parameters of the atomic positions are given, but the important bond angle $\mathrm{Si}-\mathrm{O}-\mathrm{Si}$ is not mentioned. A more detailed crystal-chemical consideration of the minerals in question would therefore be highly desirable in the next edition.

\section{Mineralogisches Institut}

Technische Hochschule

Kaiserstrasse 12

Karlsruhe

Germany

H. JAGODZINSKI

\section{Globular protein molecules: their structure and dynamic properties. By $J_{A C O B} S_{E G A L}$,} KäTe Dornberger-Schiff and ANGel Kalaidjiev. Translated by Anthony Wooster. Pp. xiii +150. Berlin: VEB Deutsche Verlage der Wissenschaften. 1960. Price DM 19.80.

Many of us working on protein crystals have in the past speculated on the structure of protein molecules and have built models, more or less precise, which seemed to us to fit the known experimental properties of proteins. This book describes the development of one such model, 'the Faltentrommel' model, by a biologist, Jacob Segal, an X-ray crystallographer, Käte Dornberger-Schiff, and a biochemist, Angel Kalaidjiev. In this model, the peptide chains are imagined to occur in comparatively short lengths in proteins, packed anti-parallel to one another and connected by diketopiperazine bridges which involve the diamino and dicarboxylic acid residues. The sheet-like structure that results is folded round to form a drum, giving a central hole, which may have a quite irregular shape, in the molecule. Large molecules are thought to consist of a number of drum-like regions. Physical and chemical evidence, enzymatic behaviour and X-ray analytical data are discussed in relation to the model.

It seems to me, as I imagine it must to many other 